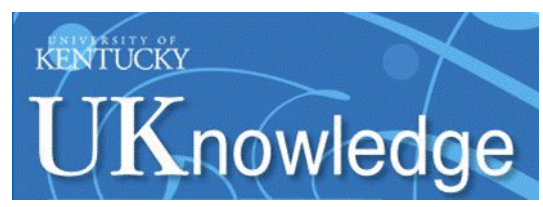

University of Kentucky

UKnowledge

Summer 7-19-2018

\title{
Sustainable Stewardship: A Collaborative Model for Engaged Oral History Pedagogy, Community Partnership, and Archival Growth
}

Janice W. Fernheimer

University of Kentucky, jfernheimer@uky.edu

Douglas A. Boyd

University of Kentucky, doug.boyd@uky.edu

Beth L. Goldstein

University of Kentucky, beth.goldstein@uky.edu

Sarah Dorpinghaus

University of Kentucky, sarah.dorpinghaus@uky.edu

Follow this and additional works at: https://uknowledge.uky.edu/libraries_facpub

Part of the Archival Science Commons, Educational Methods Commons, Oral History Commons, and the Rhetoric and Composition Commons

Click here to let us know how access to this document benefits you.

\section{Repository Citation}

Fernheimer, Janice W.; Boyd, Douglas A.; Goldstein, Beth L.; and Dorpinghaus, Sarah, "Sustainable Stewardship: A Collaborative Model for Engaged Oral History Pedagogy, Community Partnership, and Archival Growth" (2018). Library Faculty and Staff Publications. 306.

https://uknowledge.uky.edu/libraries_facpub/306

This Article is brought to you for free and open access by the University of Kentucky Libraries at UKnowledge. It has been accepted for inclusion in Library Faculty and Staff Publications by an authorized administrator of UKnowledge. For more information, please contact UKnowledge@lsv.uky.edu. 


\section{Sustainable Stewardship: A Collaborative Model for Engaged Oral History Pedagogy, Community Partnership, and Archival Growth}

\section{Digital Object Identifier (DOI)}

https://doi.org/10.1093/ohr/ohy052

\section{Notes/Citation Information}

Published in The Oral History Review, v. 45, issue 2, p. 321-341.

(c) The Author(s) 2018. Published by Oxford University Press on behalf of the Oral History Association. All rights reserved.

The copyright holders have granted the permission for posting the article here.

This is a pre-copyedited, author-produced version of an article accepted for publication in The Oral History Review following peer review. The version of record, Fernheimer, J. W., Boyd, D. A., Goldstein, B. L., \& Dorpinghaus, S. (2018). Sustainable stewardship: A collaborative model for engaged oral history pedagogy, community partnership, and archival growth. The Oral History Review, 45(2), 321-341, is available online at: https://academic.oup.com/ohr/article-abstract/45/2/321/5056316 and https://doi.org/10.1093/ohr/ohy052. 


\title{
Sustainable Stewardship: A Collaborative Model for Engaged Oral History Pedagogy, Community Partnership, and Archival Growth
}

\author{
Janice W. Fernheimer, Douglas A. Boyd, Beth L. Goldstein, and Sarah Dorpinghaus
}

Abstract: Our University of Kentucky team of professors, archivists, and oral historians have collaborated since 2013 to develop pedagogy that enables students to encounter and engage oral history, archival materials, and local community in meaningful ways. Through the impetus of the Jewish Kentucky Oral History Project and several semesters of collaboration and iterative syllabus design, we developed "sustainable stewardship" as a replicable model for course and project design to engage undergraduates in original knowledge production while simultaneously fostering archival access and growth. In this article we trace the evolving pedagogical conversations inspired by the classroom introduction of OHMS (Oral History Metadata Synchronizer), the questions of continuity they elicit, and our team's development of sustainable stewardship to respond to those questions. We argue that sustainable stewardship provides a model to connect the classroom, community, and the archive in enduring, mutually beneficial, and transformative ways.

Keywords: archive, community, sustainable stewardship, undergraduate research

Our University of Kentucky team of professors, archivists, and oral historians have collaborated since 2013 to develop pedagogy that enables students to encounter and engage oral history, archival materials, and local community. Through the impetus of the Jewish Kentucky Oral History Project and several semesters of collaboration and iterative syllabus design, we developed a model we term sustainable stewardship to engage undergraduates in original knowledge production while simultaneously fostering archival access and growth. In this article 
we begin with the evolving pedagogical conversations inspired by the classroom introduction of OHMS (Oral History Metadata Synchronizer), the questions of continuity they elicit, and our team's development of a model that responds to those questions.

Although OHMS is a digital tool originally created to enhance access to archived oral history, innovative pedagogical applications of this open-source platform have provided new ways to engage students with questions that have long plagued archivists and oral historians alike--how best to make extant oral histories discoverable and more readily available to a wider public, how to teach students best practices for engaging in this work, and how to do so ethically. ${ }^{1}$ Numerous classroom/archive partnerships are empowered by the new opportunities OHMS affords, and professors from a variety of disciplinary backgrounds (oral history, history, rhetoric and composition, folklore, digital humanities, library and information science, and education) have begun to experiment with the pedagogical possibilities. ${ }^{2}$ In 2015 , Boyd, Fernheimer, and Dixon argued that using OHMS to index oral histories provides students with opportunities for critical engagement that offer a rich, interactive, and inspiring oral history

\footnotetext{
${ }^{1}$ Douglas A. Boyd, "OHMS: Enhancing Access to Oral History for Free," Oral History Review 40, no. 1 (2013): 95 106; Boyd, “'I Just Want to Click on It to Listen': Oral History Archives, Orality, and Usability," in Oral History and Digital Humanities: Voice, Access, and Engagement, ed. Douglas A. Boyd and Mary A. Larson (New York: Palgrave Macmillan, 2014), 77-96.

${ }^{2}$ While this article recounts the way the conversation unfolds specifically around OHMS in oral history corners, complementary conversations are evolving in rhetoric and composition about best practices for using oral history and archives in writing classes. See also Deborah Mutnick, "Pathways to Freedom: From the Archive to the Street," College Composition and Communication 69, no. 3 (February 2018): 374-401, and her bibliography; Laurie Grobman, "(Re) Writing Local Racial, Ethnic, and Cultural Histories: Negotiating Shared Meaning in Public Partnerships," College English 77, no. 3 (January 2015): 236-258; Brad E Lucas and Margaret L. Strain, "Keeping the Conversation Going: The Archive Thrives on Interviews and Oral History," in Working in the Archives: Practical Research Methods for Rhetoric and Composition, ed. Alexis E. Ramsey (Carbondale: Southern Illinois University Press, 2009), 259-277. For an article that engages scholars across disciplinary boundaries - oral history, archives, and rhetoric/composition - see also Jill Goodman Gould and Gail Gradowski, "Using Online Video Oral Histories to Engage Students in Authentic Research," Oral History Review 41, no. 2 (Summer/Fall 2014): 341-450.
} 
classroom experience to undergraduates without requiring students to conduct interviews themselves. ${ }^{3}$

In his 2016 article, "Teaching Digital Humanities with Oral History: The Staring Out to Sea Oral History Project and OHMS in the DH Classroom," Dan Royles highlighted ways that implementing OHMS in undergraduate courses can help instructors return elements of the humanities to digital humanities (henceforth $\mathrm{DH}$ ) by providing means to "amplify voices from the margins in the digital humanities and ensure that our projects do not merely reinforce chauvinistic ideas about whose voices matter." ${ }^{, 4}$ Royles focused on the DH aspects of history writing, which include critical engagement with metadata, markup, and hosting.

Most recently, in their 2017 article, "Connecting the Classroom and the Archive: Oral History, Pedagogy and Goin’ North,” Jannekan Smucker, Doug Boyd, and Charles Hardy III recounted their team's combined methods for interview indexing and digital exhibit curation using OHMS and Omeka, an open-source platform for sharing digital collections, to implement a robust workflow and online exhibit. ${ }^{5}$ Although their award-winning, cross-institution collaboration showcases possibilities for engaging students in sophisticated digital narrative composition and enabling them to connect oral histories with contextualizing archival materials, it also calls attention to the challenges of creating models that endure beyond a few semesters. What happens, for example, when students have completed their assignment to index a collection

\footnotetext{
${ }^{3}$ Douglas A Boyd, Janice W. Fernheimer, and Rachel Dixon, "Indexing As Engaging Oral History Research: Using OHMS to 'Compose History' in the Writing Classroom," Oral History Review 42, no. 2 (Summer/Fall 2015): 352367.

${ }^{4}$ Dan Royles, "Teaching Digital Humanities with Oral History: The Staring Out to Sea Oral History Project and OHMS in the DH Classroom," Oral History Review 43, no. 2 (Summer/Fall 2016): 408-420.

5 Janneken Smucker, Douglas A. Boyd, and Charles Hardy III. "Connecting the Classroom and the Archive: Oral History, Pedagogy, and Goin' North," Oral History in the Digital Age, 2017, http://ohda.matrix.msu.edu/2017/02/connecting-the-classroom-and-the-archive-oral-history-pedagogy-goin-north/
} 
of oral histories, but the professors, students, archive, and community all wish to continue the collaboration?

Charlotte Nunes's 2017 article, “'Connecting to the Ideologies that Surround Us': Oral History Stewardship as an Entry Point to Critical Theory in the Undergraduate Classroom," gestured toward the need to move beyond a one-off partnership and introduced "stewardship" as a valuable framework for thinking about the relationships students can help to build with archival repositories and community partners alike. She argued that oral history stewardship can be "an effective conduit to theoretically engaged pedagogy." However, for her, two components make stewardship especially powerful--first, the postcustodial component, which "represents a significant break from the tradition of archival custody" where now "a repository manages but does not own a community's archives," and second, the "ongoing collaborative relationship."6 Our team's approach builds upon Nunes's conceptualization of stewardship, especially the ongoing collaborative relationship component, and transforms this method by introducing a sustainability component.

Sustainable stewardship provides a model whose sustainable aspects are built on mutually empowering collaborations in which an explicit institutional and community commitment is shared by the classroom, the archive, and the community. Sustainability entails creating a permanent, accessible home for the materials produced while also leaving room for collaboration among researchers, professors, students, archivists, and community members to ebb and flow as needed. The archival partners add a profound commitment to preservation and development to the collection model; they extend the temporal aspects of Nunes's ongoing collaborative relationships to sustained curation-long-term preservation and the commitment to

\footnotetext{
${ }^{6}$ Charlotte Nunes, “'Connecting to the Ideologies that Surround Us': Oral History Stewardship as an Entry Point to Critical Theory in the Undergraduate Classroom," Oral History Review 44, no. 2 (Summer/Fall 2017): $351,355$.
} 
provide continuous, innovative access to the materials created and collected by this partnership. ${ }^{7}$ Not all projects and partnerships that include students are designed to be continuous, as many classroom/community oral history initiatives are constrained by the hard limits of academic quarters or semesters and the continuous cycling of new students. Our sustainable stewardship transcends the short-term classroom/community/archive partnership. It is possible precisely because the curricular components were developed in partnership with the Louie B. Nunn Center for Oral History and the University of Kentucky Libraries Special Collections Research Center (SCRC) archival holdings.

For our particular collaboration, the community partnership with a land-grant, flagship university matters. As a land-grant institution, the University of Kentucky (UK) has a mandate for education, accessibility, economic development, and research, as well as cultural and societal advancement in service to the public. Linking the classroom, the oral history center, and the archive in a cyclical partnership with the local community honors our land-grant mission as we develop a multidimensional opportunity for sustainable stewardship. This model creates ongoing collaborative relationships that enable long-term continuity on multiple, synergistically integrated levels. In short, sustainable stewardship is a model that engages students, communities, and archives in continual collaboration to enhance access to and discovery of extant archived interviews while simultaneously growing the oral history and archival holdings.

\section{The Jewish Kentucky Oral History Initiative}

An initial collaboration in 2013 between Dr. Janice W. Fernheimer, associate professor of writing, rhetoric, and digital studies and director of Jewish studies, and Dr. Doug Boyd, director

\footnotetext{
${ }^{7}$ Nunes, 355 .
} 
of the Louie B. Nunn Center, focused on developing a method for students to use OHMS as a pedagogical tool to index oral histories from the Nunn Center's collection in the context of required writing courses. In this first iteration, utilizing OHMS indexing as part of a series of scaffolded writing assignments enabled students to access and interact with primary archived interviews as a means to better understand writing for particular audiences. It also guided students to "actively produce knowledge" and "compose history."8 Through 2013-2014, our team expanded to include education policy scholar Dr. Beth L. Goldstein, the Jewish Heritage Fund for Excellence, Sarah Dorpinghaus, director of digital services and curator of the Jewish Kentucky heritage collection, and local Jewish community members to launch the Jewish Heritage Fund for Excellence (JHFE) Jewish Kentucky Oral History Initiative. Our focus has iteratively evolved to create a model for sustained interaction, increased access, and continued growth for collections - a model for sustainable stewardship. To present the model, we will describe the project that prompted its development. We will outline our team's workflow and then show how oral history collection and pedagogical innovation prompted community partnerships, demonstrating how sustainable stewardship works as a model for collaboration with communities beyond the university's walls.

Spearheaded by Fernheimer and Goldstein, the three-year, JHFE Jewish Kentucky Oral History Project was initially imagined in collaborative partnership with the Nunn Center to record, archive, transcribe, and index a minimum of fifty-five oral histories over the course of three years (2015-2018). As of spring 2018, the digitized and publicly accessible collection included seventy-eight interviews, and it continues to grow. We have successfully piloted the

${ }^{8}$ Boyd, Fernheimer, and Dixon, 352-367. 
integration of students both as indexers and interviewers, and we are developing a way for local Jewish community members to index and interview as well.

The goals of the larger project were to establish an oral history collection of Jewish Kentuckians' voices that would highlight the diversity, depth, and complexities of Kentucky Jewish identities and experiences across the Commonwealth of Kentucky — in Lexington and Louisville (historically and currently the largest Jewish population centers in the state), in rural and urban areas, as well as in historic Jewish communities (Paducah, Danville, Harrodsburg, Bardstown, and Bowling Green). The interviews would span areas of professional expertisemedicine, entrepreneurship, the bourbon industry, agriculture, and Jewish communal life, as well as topics of specific interest—for example, college student life, civil rights, and the junk business. We also aimed to include changes for men, women, and their communities across time. With a small sample relative to the scope we hoped to cover, and a limited timeframe for the funded project, we prioritized the most senior members of the Jewish community to capture their stories before the individuals were no longer able to tell them.

Key to our project design was a model for continued growth that would extend beyond the funded period provided by the grant. To enable this growth, we envisioned two components: community participation and a companion undergraduate course, Writing Jewish Kentucky, through which students would contribute to the project. $^{9}$

The pedagogical design that supports sustainable growth relies on establishing and maintaining community partnership in this project. Yet there is no one community that actually

\footnotetext{
${ }^{9}$ Although we began with an honors version of a required first-year writing course, Writing Jewish Kentucky, which Dr. Fernheimer designed and taught in spring and fall 2017 (http://wrd112.fernheimer.org), we continued to experiment with course design in spring 2018 when Dr. Fernheimer designed and taught Composing Oral History, an upper-division course that fulfills degree requirements for both writing, rhetoric, and digital studies and English education majors (http://oh.fernheimer.org).
} 
constitutes "the partner." While the larger JHFE Oral History Project has had a statewide scope, aiming both to include and represent Jewish voices from across the commonwealth, for the purposes of facilitating classroom/community connections we narrowed our scope to the greater Lexington-area Jewish population to pilot and implement the sustainable stewardship model. This geographic location was chosen for the focus of the pilot because of the proximity to the people to be interviewed, the organizations that would participate, and the students at UK. Although this Lexington-area Jewish population is sometimes referred to as the Jewish community of central Kentucky, in fact, it is comprised of several thousand individuals representing a wide diversity of cultural, occupational, and observance orientations, as well as a variety of both well-established and loosely formed organizations whose memberships overlap but are not identical. Examples include Temple Adath Israel Congregation, Ohavay Zion Synagogue, Lexington Havurah, Jewish Federation of the Bluegrass, Lexington Hadassah, and Lexington B'nai B'rith Lodge. One of our challenges, therefore, has been to understand the diverse components of this "community" so as to situate the project in mutually beneficial relationships with it.

We used several approaches to establish those relationships and to explore ways different groups in the area might become partners. Janice Fernheimer and Beth Goldstein were uniquely situated as both project designers in their faculty roles at the University of Kentucky and active members of the Lexington Jewish communities whose archive they hoped to build. These dual roles created an early bridge between the communities and the university. During the first year of conducting oral histories, they hired two additional experienced interviewers with established ties to Jewish Lexington: Janice Crane is a second-generation Lexingtonian who grew up and raised her children in one of the local synagogues; Arwen Donahue had completed oral histories 
of Holocaust survivors and Jewish social activists in the area. ${ }^{10}$ Both Crane and Donahue had significant oral history interviewing experience from previous oral history projects with the Nunn Center going back to the 1980s. Their personal ties with and knowledge of Jewish Lexington helped to establish the project's trustworthiness and build local interest. In the project's first year, our broader professional team (Fernheimer, Crane, and Donahue, and later Dr. Carol Ely of Louisville) conducted interviews, thus helping both to increase the collections' number of interviews and to strengthen ties with Kentucky Jewish community members. When we began offering Writing Jewish Kentucky in the spring of 2017 in the project's second year, we added students to our team of interviewers. They conducted original oral histories as part of the course requirements. ${ }^{11}$ Community members were more willing to volunteer for the studentconducted oral histories in part because the project's value was established for the community and in part because community members valued and enjoyed helping students learn about the Jewish community, thereby becoming "teachers" of these students.

Fig. 1. Community members and students working together. From left to right: Lowell Nigoff, Garry Hoover, Allison Gant, Morgan Weilbacher. (Photo by authors.)

Parallel to the oral history project, the University of Kentucky Special Collections Research Center charged Sarah Dorpinghaus to spearhead an archival collecting initiative focused on photographs, organizational records, and manuscript collections documenting the culture and history of Kentucky’s Jewish communities. Dorpinghaus had previous experience working with the archives of Jewish synagogues and communities in South Carolina but was unfamiliar with

\footnotetext{
${ }^{10}$ Arwen Donahue and Rebecca Gayle Howell, This is Home Now: Kentucky's Holocaust Survivors Speak (Lexington: University of Kentucky Press, 2009).

11 The funding years for the project correlated with the calendar rather than the academic year; our funding covered January 2015-December 2017, with a no-cost extension through spring 2018 to enable us to pay for the Kentucky Jewish History Symposium.
} 
those of Kentucky. Fernheimer and Goldstein's work provided entrees for UK SCRC's collecting initiative, especially since Dorpinghaus was not herself a member of the local community. The momentum of the oral history project provided opportunities for established Jewish organizations in the area to discuss the donation of related archival materials. To date, Temple Adath Israel Lexington, the Jewish Federation of the Bluegrass, and Ohavay Zion Synagogue have donated their archival materials to UK SCRC. With the assistance of university archivists, members of those organizations reviewed their records to determine what they would donate, what could be made publicly available, and what should remain with the organization. These conversations have helped the community institutions think about what to preserve, how, and in what venues. Similarly, the discussions have sparked community members' reimagining of their roles in student learning. Additionally, some community members are now working with our team to initiate and conduct oral history interviews within their respective organizations for the project, a process we detail later in this article.

\section{Pedagogical Model and Assignment Sequences}

Our team sought to develop a model for collection and access that would bring undergraduates from across the disciplines into public writing and enable sustainable collection growth for researchers, archivists, students, and community members. Building on the model piloted by Fernheimer and Boyd in 2013, our team wanted to introduce a way for the oral history collection to continue to grow as it was also being made more accessible through student indexing of interviews using OHMS. Our pedagogical model had several goals: 
1. To utilize oral history to introduce a mostly non-Jewish student population from a variety of disciplinary backgrounds to Kentucky Jewish heritage by working directly with the collection and the Jewish community

2. To expand public access to the extant oral history interviews through student-authored metadata

3. To grow the oral history collection itself through student-conducted interviews

4. To enable hands-on learning, authentic research experiences, original knowledge production, and public writing as well as potential professional development opportunities (experience with new technologies and skills, conference and public presentations, and publishing, for example)

5. To embed the pilot courses into the university curriculum to institutionalize implementation of this model

6. To connect the Nunn Center, the archive, and the community in order to collaborate on the preservation and access of archival collections beyond the oral histories In spring and fall 2017, we further revised the pedagogical model and accompanying assignment sequence to include both indexing and conducting original oral history interviews. Students completed a scaffolded assignment sequence in six stages. This sequence helped them acquire the requisite rhetorical skills to complete the assigned tasks successfully while also introducing them to Jewish culture, history, and heritage through the oral histories' content. The rhythm for the course's workflow was set early in the semester, with an introduction to oral history as a method and (American) Jewish history as a subject through exposure to interviews in the Jewish Kentucky Oral History Project and class discussions of scholarly readings selected to 
establish the importance of oral history, the broad narratives of Kentucky Jewish history, and how those narratives fit into both American and Jewish history more generally.

Before students began to work closely with a specific interview that they would index either individually or with a peer, we read Alessandro Portelli's "What Makes Oral History Different” and Nora Rose Moosnick’s “On Being a Documentarian,” the latter a reflective postscript to her Arab and Jewish Women in Kentucky: Stories of Accommodation and Audacity, a book based on an oral history project Moosnick conducted between 2006-2008. ${ }^{12}$ Thus primed with an introduction to what oral history is and does, students then selected an already indexed interview and listened closely to generate research questions based on the interview's content. Next, as a class we read and discussed selected essays about Jewish Kentucky authored by historians Lee Shai Weissbach (who was also interviewed for the collection) and Louis Dembitz to put Kentucky's Jewish history in context. Throughout the semester, we continued to oscillate between the specific stories and descriptions students encountered in the oral histories and the broader scholarly essays that helped contextualize those stories. Through this intertextual reading, listening, and discussing, we aimed to deepen students' understandings of the broad historical themes through close interactions with the specifics told by an interviewee, while also allowing students to develop their own expertise. This pattern was also meant to foster a generative process whereby students would follow their own curiosity by raising their own research questions and conducting further research to answer these questions. ${ }^{13}$ Since Writing

\footnotetext{
${ }^{12}$ Alessandro Portelli, "What Makes Oral History Different," in The Oral History Reader, $3^{\text {rd }}$ ed., ed. Robert Perks and Alistair Thomson (New York: Routledge, 2016); Nora Rose Moosnick, "Postscript: On Being a Documentarian," in Arab and Jewish Women in Kentucky: Stories of Accommodation and Audacity (Lexington: University Press of Kentucky, 2012), 181-188. The full reading list and weekly schedule for the course can be found at http://wrd112.fernheimer.org/?page id=13.

${ }^{13}$ In rhetoric and composition, we identify this kind of idea-generation as a model for rhetorical invention, where invention is one of the five canons (the other four are arrangement, style, memory, and delivery) for creating and revising texts.
} 
Jewish Kentucky was offered as a special section of an honors first-year writing course, WRD 112, which has its own specified learning outcomes and objectives, our teams' goals were interleaved into the broader course goals for increasing students' ability to conduct academic research as well as critically engage and compose texts across media.

\section{Stage 1: Authenticating Transcripts and Creating Indexes for Extant Interviews}

After their initial introduction to oral history, Jewish history, and writing as a process of recursive revision, students learned even more about Kentucky's Jewish history and community by making rhetorical and interpretive decisions during both transcript authentication and OHMS index creation. They selected an interview guided by their research interests and the topics discussed, and they were tasked with following the Nunn Center's style guides to "authenticate" a transcript created by a third party. ${ }^{14}$ Through this transcript authentication process, students learned to carefully listen to confirm that the written transcript was a verbatim representation of the recorded interview: they checked name spellings and comma placements and developed an awareness of the way both punctuation and the inclusion of nonverbal utterances shape meaning in transcripts. For example, if an interviewee laughed in the course of the interview and the transcript did not make note of the laughter, the students revised the transcript to represent these and other nonverbal utterances in the interview. They could see clearly how much difference it could make to the meaning of what was said if the speaker laughed, and thus they came to understand through practice how the exact preservation of an utterance or the placement of a comment or comma in the transcript could transform meaning. As students grew accustomed to the ways their interpretive choices shaped the metadata they created, they also became more

\footnotetext{
${ }^{14}$ During the period of JHFE funding (2015-2018), these transcripts were paid for by the JHFE grant and the Nunn Center.
} 
critically aware of the way that history is authored and of the role they were playing in its composition.

After authenticating the transcript, they worked to create digital, searchable OHMS indexes for the interviews. This process required them to break the interview into smaller segments and create metadata for each segment. The metadata they provided included a partial transcript, keywords, a segment synopsis, and in many cases a contextualizing hyperlink or set of GPS coordinates.

Fig. 2. Screenshot of OHMS Viewer showing index segment of interview with Madeline Abramson. To see the index in action, go to https://kentuckyoralhistory.org/catalog/xt7f7m041n26.

Once they created draft indexes, students received feedback from their peers, their instructor, and in some cases other members of our broader research team, thus becoming part of a professional collaborative process. Their labor generated texts - the OHMS index and the overall interview description - aimed toward a public audience.

When authoring interview indexes, some students struggled at first to generate effective key words, or were hesitant to use key words that the interviewee did not use specifically and that therefore did not appear in the transcript. For example, there were times when interviewees described experiences that resulted from prejudiced behavior, but for various reasons the interviewees did not explicitly identify these experiences as anti-Semitic. Students' introduction of anti-Semitism as a key word thus helped make such interviews more readily available to researchers seeking to learn more about anti-Semitism, its occurrence in the South, and the way it influences Kentucky Jewish experiences. In these contexts, students introduced key words to make the segments more easily discoverable for a researcher. As the semester progressed, they 
began to see themselves as translators of sorts, responsible for the metadata processes of "mapping natural language conversation to descriptive and meaningful concepts" and ensuring that the indexes would help potential researchers discover and locate relevant interviews. ${ }^{15}$

Additionally, students helped further develop the controlled vocabulary thesaurus originally created by Fernheimer and Goldstein for use with the OHMS indexing module. Fernheimer and Goldstein initially generated a thesaurus of terms that might otherwise prove difficult for an unfamiliar audience. For example, they included place names for religious organizations and institutions, synagogue titles, Yiddish and Hebrew words, and Jewish holiday names, among other terms. Students enabled the thesaurus to grow in a sustainable way along with the collection itself by highlighting words they encountered in interviews that were not yet part of the thesaurus, such as new family and place names. By identifying such heretofore missing words and sending them to the broader team for inclusion in the thesaurus, they helped ensure sustained growth of the collection's controlled vocabulary. After each major assignment, students were also required to write a reflective essay, drawing connections between their own interpretive work and the larger work of writing history—connecting what they did to what they learned. In Writing Jewish Kentucky, they authored a reflective essay after indexing, interviewing, and collaboratively authoring an audiocast. ${ }^{16}$ These reflective essays encouraged students to think critically about what and how they learned.

Stage 2: Rhetorically Analyzing Interviews

After working closely with the transcripts and the indexes, students then authored rhetorical analysis essays which allowed them to focus on the ways oral history helped the interviewees

\footnotetext{
${ }^{15}$ Boyd, “OHMS: Enhancing Access," 100.

${ }^{16}$ The specific prompts for these assignments are available at http://wrd112.fernheimer.org, and in slightly revised and updated form at http://oh.fernheimer.org/?page $\mathrm{id}=6$.
} 
narrate their sense of identity. Such rhetorical analysis brought depth and sophistication to students' initial observations about the ways interpretation plays a key role in how others' narratives are represented in transcripts and indexes. It also focused students' attention on the ways these narratives intersect with broader historical events and context.

\section{Stage 3: Historical Research}

After attentive listening and interpreting, the students moved on to assignments requiring deeper research. In this stage, students worked to better understand the way identity narratives are created in response to broader historical events and context; assignments prompted students to generate their own research questions to learn more about the issues raised in the interviews. Religious segregation, racial segregation and integration in the South, entrepreneurship, campus Greek life, the evolution of campus life and Lexington as a city, and the role of feminism in Jewish religious, institutional, and family life are some of the topics they investigated.

\section{Stage 4: Collaborating to Modify the JHFE Interview Protocol Template}

Led by their own questions, students then worked collaboratively with a small group to identify a community member from an instructor-provided (and preapproved) list whom they would like to interview. To create this list, Fernheimer and Goldstein identified community members who would be willing to be interviewed by students, who were able to speak to and deepen students' knowledge of topics students identified to be of high interest, and who they thought were likely to generate strong interviews. Fernheimer then contacted these community members prior to the distribution of the interview assignment to confirm they were both willing and able to work within the constraints of the semester's rhythm. In this way, Fernheimer and Goldstein's knowledge of community members' interests, history, and professional experience enabled them to provide strong possibilities for students to learn about student-generated research areas. In 
collaboration with Fernheimer and Goldstein, students researched each selected individual to create a tailored interview protocol based on the template provided. Most protocols underwent several rounds of revision before receiving final approval from Fernheimer and Goldstein.

\section{Stage 5: Conducting Original Oral Histories}

The Nunn Center provided students and interviewees with access to their professional recording studio to enable the highest possible audio quality. Students coordinated among themselves, the studio staff, and the interviewee to schedule a time convenient for all. Students then met with their chosen individual to conduct the oral history interview, which became part of the JHFE collection after it was turned in with the requisite release forms. In the subsequent offering of the course, new students authenticated and indexed these student-generated oral histories for public use. $^{17}$

\section{Stage 6: Creating Topical Audio Narratives}

In larger groups of four to six, students conducted research in primary and secondary materials to generate an annotated bibliography about a set of oral histories - their historical eras and the issues and questions they raised. After conducting their research and original oral histories_-by then part of the Nunn Center collection-students in the 2017 courses worked in their larger groups, weaving together multiple oral histories to generate contextualizing audiocasts of ten to twenty minutes. These audiocasts were designed with a public audience in mind and often were aimed at other UK students. They introduced the audience to the oral histories, the issues they present, and the broader collection which houses them. ${ }^{18}$

\footnotetext{
${ }^{17}$ In a few instances interviewees opted to restrict access to the interviews because of sensitive material that came up during the interview. In these cases, students learned firsthand about the ethical concerns that arise with oral history collection.

18 The full syllabus and assignment prompts for the first-year writing course available at http://wrd112.fernheimer.org. A selection of student-authored audiocasts is available at http://www.nunncenter.net/jewishkentucky/collections/show/3.
} 
Since we began this pedagogical experiment, the UK SCRC has experienced significant collection growth in Jewish materials about central Kentucky, inspired by the JHFE Oral History collection, as described earlier. The archived materials not only fill a documentary gap in SCRC's holdings, but also support ongoing research and learning about central Kentucky's Jewish communities, including for the students in the Writing Jewish Kentucky courses. They have enabled further pedagogical innovation and archival integration.

A more recent pedagogical iteration of stage 6, implemented in spring 2018, invited advanced undergraduates to digitize, create metadata for, and digitally curate the recently acquired Jewish community primary materials in Omeka-based online exhibits. ${ }^{19}$ This new assignment introduced students to conducting research using archival materials in a special collections setting while also providing them an opportunity to curate materials digitally for a broader public. Integrating Omeka with OHMS, and thus also the oral histories with the archival materials, positions us to create several other innovative pathways for sustainable stewardship. ${ }^{20}$ By developing a framework through which students participate in the creation of primary sources and metadata, sustainable stewardship presents a model that enables projects to continue to engage students and communities while at the same time augmenting archival holdings and making them more accessible. The model we detail above outlines how students' contributions facilitate both the increased access to and the creation of new materials. In fact, their work to create improved access—-whether by indexing or digitally annotating in Omeka—prepares them to conduct better oral history interviews and discover additional archival materials. Just as using

\footnotetext{
${ }^{19}$ The syllabus for the upper division course, Composing Oral History, which incorporates the use of Omeka and the integration of OHMS, is available at http://oh.fernheimer.org.

${ }^{20}$ Doug Boyd and Janneken Smucker worked with the University of Kentucky digital library architect Eric Weig to develop a suite of plug-ins and themes that integrate OHMS and Omeka; see details at http://www.oralhistoryonline.org.
} 
OHMS to index interviews prepares them to conduct their own oral history interviews, the discovery of archival materials is designed to help students be more conscientious facilitators of broader public discovery and access. Students learn about culture, heritage, institutions, and observances; this subject-specific knowledge prompts them to have their own questions and agency as researchers. Undergraduate student Amanda Holbrook explained:

While working on this project, I have learned a lot. I've learned about the Jewish community, but more importantly, I've learned about how to take an uncommon topic that may not seem very interesting at first glance and make it more intriguing. I have also learned about podcasts, a medium I was not very familiar with before, and how they are able to deliver information to the general public in today's world in a more practical way than essays and books. Most importantly, I've learned about how to conduct research on a topic that I was not at all familiar with to start and tell a story about people and a community that I have never known. ${ }^{21}$

As Holbrooke emphasizes, these classroom experiences do more than simply teach students methods for conducting research. They teach students about communities by requiring them to engage with and ethically represent these communities to a broader public in new media.

\section{Emerging Model for Community-Led Sustainable Stewardship}

We have approached sustainable stewardship from multiple directions by augmenting Jewish heritage oral history interview and archival collections and by expanding access through digitization, indexing, and the creation of online exhibits. These approaches are guided by our dual commitments: to bring students into the research and knowledge production process in

\footnotetext{
${ }^{21}$ Amanda Holbrook, "Podcast Reflective Essay," student paper written to fulfill an assignment in WRD 112, University of Kentucky, May 1, 2017, 3.
} 
pedagogically dynamic ways, and, driven by our land-grant mission, to undertake projects that directly engage the university's public constituencies. In our model of sustainable stewardship these two commitments are deliberately designed to intersect.

Collaborations and partnerships come in many forms and develop over time. We began, of course, with the interdisciplinary collaboration within the university across disciplines and units - faculty with Jewish studies interests from both arts and sciences and education, and oral historians and archivists from the libraries. With our base in the university, from the start our model included exploring ways to bring students into the work of collection growth, curation, and discovery. While the focus has been primarily on the undergraduate pedagogy described above, graduate students from several disciplines have also contributed to the archival research, editing, and production of materials for public presentation, sometimes in collaboration with the undergraduates. Students have presented research conducted in these courses at national conferences including the Rhetoric Society of America, the Southern Jewish History Symposium, and the Kentucky Jewish History Symposium, and project-based publications are forthcoming.

A dynamic community-based collection depends on establishing working relationships with relevant community organizations and individuals. These partnerships result in shared information, guidance, preservation, efficiencies of effort, and community building, as well as resources in the forms of funding and skilled and volunteer labor. Within the Bluegrass area, with its relatively small Jewish organizational infrastructure, we have sought to connect with all the community organizations to create an archive of organizational records that links to oral histories of Bluegrass Jews. While we began with senior individuals with diverse backgrounds 
and histories, the students' interests have now led to a much more multigenerational oral history representation of Central Kentucky's Jewish population.

These two strands - courses as sites for student engagement in the collection and with individual community members through interviewing and curating, and community partnerships as ways to gather, generate, and discover the collection - come together in important ways for sustainable stewardship. Through indexing extant oral history interviews, completing background preparatory research, and conducting new interviews of community members, the students both augment the collection and draw closer to the Jewish communities, institutions, and people they study. Students learn the connection between archived materials and actual community members. Undergraduate student Saisindhu Marella reflected:

At the start of the semester, I honestly didn't know much about Jews or Judaism. In fact, I thought the Jewish community present in Lexington was much smaller than it actually is. This increase in knowledge about the Jewish community in Kentucky and Judaism started with an oral history about Mark Bronner. ${ }^{22}$ I have carried that oral history for a few months and have used it to complete many other assignments in this course as well as create the final project, the podcast. At the end of this course, I know that I will have made an impact by adding to the rich Jewish history in Kentucky through my indexing of Bronner's interview, conducting Elizabeth Bronner Crane's interview, and creating a podcast. $^{23}$

As Marella's remarks demonstrate, contact with community members significantly enriches students' classroom learning.

\footnotetext{
${ }^{22}$ To listen to Mark Bronner's oral history, click here: https://kentuckyoralhistory.org/catalog/xt73ff3m048s.

${ }^{23}$ To listen to Elizabeth Bronner Crane's oral history, go to https://kentuckyoralhistory.org/catalog/xt7kd50fxs0x; Saisindhu Marella, untitled student paper written to fulfill an assignment in WRD 112, University of Kentucky, April 30, 2017, 1.
} 
As another step in this process, community members who have helped to create the institutional archives are now coming to the university to help guide the students through the archived materials. For both the students and the community members, meeting and talking faceto-face enhances the pedagogical value of the collection as living history in real community. It highlights the way the expanding archive becomes a space for shared discovery.

In the case of the Lexington Havurah, another model of partnership between the Jewish community, the Nunn Center, and UK SCRC is emerging. The Havurah was founded in 1978 as a member-led, egalitarian "congregation" that would meet to provide spiritual, educational, and social activities for its members without hired staff or a fixed space. ${ }^{24}$ In keeping with its modus operandi, the Havurah decided in summer 2017 to participate in the JHFE Oral History Project and with the UK SCRC as a collaborative partner. Much as we have involved students to interview, index, and curate the collection, the Havurah now intends to work with us to interview and curate their own part of the collection with our guidance. One step will be using the accumulated archives as prompts to generate recorded group discussions about the history of the Havurah, with the interviews then becoming part of UK SCRC holdings. Another step will be to conduct and include oral histories in which Havurah members interview one another one-on-one.

Our interactions with the Louisville Jewish Community Federation, Louisville Jewish Archives Committee, Temple Adath Israel Louisville, and Jewish Family and Career Services started in 2015 as a way to learn the landscape of Jewish Louisville for the JHFE project. In the

\footnotetext{
${ }^{24}$ The Havurah movement nationally grew out of the counterculture impetus in the 1960s. In some Jewish circles, small groups of people (havurot) began to meet regularly for participatory, communally-led Jewish prayer, study, and events, often independent of established synagogues. The Lexington Havurah formed in 1978 expressly to create an egalitarian, traditional-leaning worship space in which Jewish women and men could fully and democratically participate in ritual and leadership roles. This was almost nine years before the traditional-leaning Conservative-movement synagogue in Lexington, Ohavay Zion Synagogue, allowed the equal participation of women in ritual roles.
} 
process we became familiar with extensive, community-generated interview collections. Over ninety oral history interviews were recorded through the Louisville Jewish Community Center in the 1970s and 1990s, some of which had been archived in the University of Louisville archives and special collections holdings. In addition, several other Louisville-area organizations had conducted their own oral histories, including Temple Adath Israel, Jewish Family and Career Services of Louisville, and the Filson Historical Society. We also garnered advice from Louisville Jewish community members about people whom we should interview. These conversations led to a new set of oral histories for the JHFE collection at the University of Kentucky and also inspired new partnerships and activity in Louisville, especially at the University of Louisville and the Filson Historical Society, to curate their archived oral history collections using OHMS and related digital platforms. In this sense, sustainable stewardship extends beyond owning collections to establishing working relationships that promote collaborative growth and accessible discovery beyond any single archive.

\section{Conclusion}

For decades, countless undergraduate courses have integrated oral history interviewing as an experiential aspect of course design, and numerous undergraduate courses have utilized oral history to connect with communities in an ongoing and meaningful way. More recently, OHMS has enabled oral history indexing to become part of experiential pedagogy to promote student learning about specific communities. Sustainable stewardship integrates these multiple components to provide ways to make extant interviews and other primary source materials in the archive more searchable, discoverable, and accessible while also growing the archive itself; it provides an enduring structure to increase archival holdings and student knowledge creation. The 
linchpin for sustainable stewardship as a pedagogical model is an oral history project design where the classroom, the archive, and the community connect in an integrated, committed, and collaborative partnership. Throughout the semester, students continually engage with community oral history on multiple levels: they authenticate transcripts and utilize OHMS to create indexes for interviews created by students from the previous semester; they conduct research to contextualize indexed interviews and put them in conversation with other interviews in the collection and with the broader themes and historical moments they crystallize; they prepare protocols and conduct oral histories that become part of the collection (to be indexed by future students); and they create a public, digital history narrative (either an audio podcast episode or Omeka-curated exhibit) that combines multiple oral histories with context. Students learn to listen deeply to interviews and to think critically while creating a usable digital index. Through this engaged listening they learn to become better interviewers when it is their turn to interview, as demonstrated in this sample interview with Rabbi Sharon L. Cohen, conducted by students Hannah Thompson, Trupte Patel, and Dylan Morris: ${ }^{25}$

Go to sample interview (click on the Access tab on the page linked below to listen): https://kentuckyoralhistory.org/catalog/xt780g $3 \mathrm{~h} 147 \mathrm{~g}$ While the pedagogical model developed out of work with and from the JHFE Jewish Kentucky Oral History Collection, the assignment sequence could be used in any course that seeks to emphasize continual growth of, and access to, a particular oral history collection while also connecting students, communities, as well as library and archival resources. Key to success is the commitment of all participants. With that commitment firmly in place, the model could be

\footnotetext{
${ }^{25}$ Rabbi Sharon L. Cohen, interview by Hannah Thompson, Trupte Patel, and Dylan Morris, March 31, 2017 , Jewish Kentucky Oral History Project, Louie B. Nunn Center for Oral History, University of Kentucky Libraries.
} 
adapted by other cultural heritage institutions like museums, historical societies, and public libraries.

This model provides opportunities for collaborative reciprocities to emerge on multiple levels. From the library and archive perspective, the Nunn Center and the SCRC are engaging students with oral histories and a range of other primary sources in a comprehensive research context that transcends the traditional library or archive instructional context. Using this model, entire courses are designed around oral history and archival collections, giving students, faculty, and community members the opportunities to focus on research collections and connect both broadly and deeply. By engaging the students as indexers first and then as interviewers, the framework is in place to create new interviews based on knowledge developed while processing extant interviews in the collection. When students index interviews early in the semester, they develop a frame of reference for interviewing methodologies that they apply later. In our experience, the students are less nervous and far more likely to ask thoughtful follow-up questions in their interviews in the model that includes OHMS indexing and content reflection as assignments that precede the interview experience. Again, from the archives perspective, this model has also expedited and enhanced the substantive connection between the archive and the community.

From the classroom perspective, sustainable stewardship is a framework that has empowered our faculty to design rich courses that deeply and comprehensively incorporate primary sources into course design. Undergraduate students are able to engage with the archive and with community members in a way that transforms their learning. Through this collaboration with the Nunn Center and the archive, work students do for their assignments is not simply graded, returned, and discarded or filed away; it contributes to the composition and preservation 
of public history. Students' indexes are published and digitally accessible, and authenticated transcripts are synchronized with the audio and video interviews, resulting in innovative online access to original oral history. Student names are linked with their contributions in the OHMS public records in an acknowledgments field. This model credits the students' agency in creating a very real part of the historical record, which is extensively accessed and used online. Although these students focus on only dozens of interviews each semester, they participate in an ongoing and public-facing project with significance at the local, regional, and even national levels. With sustainability in mind, we aim to move these piloted courses into the approved university curriculum. We intend to situate them so that the focal topics and areas are flexible, allowing for sustainable stewardship of the JHFE Jewish Kentucky project along with other oral history collections. Once accepted as part of the curriculum, this course would allow the JHFE Jewish Kentucky collection to continue to grow with the community while also establishing a course that enables other professors to use their own expertise and community commitments to develop other collections.

From the communities' perspective, sustainable stewardship takes an important step toward enriching the relationships between the university and local and regional communities. This collaboration has created new oral history and archival collections that document and preserve important aspects of community history and identity. More importantly, this collaboration has created a framework for building future collections in an ongoing way. The Nunn Center and the SCRC provide stability and innovation to future preservation and access for archival collections. While short-lived, "boutique" academic, archival, and community partnerships have often proven unsatisfactory, the ethic of sustainable stewardship creates 
collaborative relationships intended to connect classrooms, archives, and communities in transformative, dynamic, and reciprocally empowering ways over time.

In 2014 Boyd wrote, “In today's innovative digital climate, it seems that you can do just about anything with a grant. What you cannot do, necessarily, is sustain what you created with that grant after the grant funding runs out." 26 Sustainable stewardship provides an ongoing pedagogical framework for envisioning and implementing successful student and communityfocused oral history projects and similar classroom, archives, and community partnerships that can be sustained and, indeed, can continue to thrive in new and exciting ways, even after initial funding is gone.

Janice W. Fernheimer is associate professor of writing, rhetoric, and digital studies and the Zantker Charitable Foundation Professor and director of Jewish studies at the University of Kentucky. She is the author of Stepping into Zion: Hatzaad Harishon, Black Jews, and the Remaking of Jewish Identity (University of Alabama Press, 2014) and the coeditor of Jewish Rhetorics: History, Theory, Practice (Brandeis University Press, 2014). In collaboration with author/illustrator J. T. Waldman, she is currently researching and writing a transmedia project (historical fiction web comic and podcast series), America's Chosen Spirit, based on oral histories and archival materials that detail the influences of Jews, women, African Americans, and immigrants on the Kentucky bourbon industry. Email: jfernheimer@uky.edu

Douglas A. Boyd directs the Louie B. Nunn Center for Oral History at the University of Kentucky Libraries Special Collections Research Center and he designed and created OHMS (Oral History Metadata Synchronizer), an open-source system for enhancing access to online oral history. He is the coeditor of Oral History and Digital Humanities: Voice, Access, and Engagement (Palgrave MacMillan, 2014); the author of Crawfish Bottom: Recovering a Lost Kentucky Community (University Press of Kentucky, 2011); and editor and manager of the Oral History in the Digital Age initiative. Email: doug.boyd@uky.edu

Beth L. Goldstein is associate professor of educational policy studies and evaluation at the University of Kentucky. Within the anthropology of education, she specializes in research on educational border-crossings in both domestic and international contexts as well as in qualitative research methods. Recent publications include Action Research for Change Management in

${ }^{26}$ Boyd, "“I Just Want to Click."” 
Higher Education, a training manual published in Indonesian. With Janice Fernheimer, she has codirected the Jewish Heritage Fund for Excellence (JHFE) Jewish Kentucky Oral History Project. Email: beth.goldstein@uky.edu.

Sarah Dorpinghaus is the director of digital services at the University of Kentucky Libraries Special Collections Research Center, where she develops long-term strategies and oversees workflows for digital content creation, management, and preservation. She also serves as the curator for Jewish Kentucky Heritage at UK Libraries. Email: sarah.dorpinghaus@uky.edu. 